\title{
Negotiating new ways of developing writing in disciplinary spaces: The changing role of writing consultants at the Wits School of Education Writing Centre
}

\author{
Emure Kadenge \\ School of Education, University of the Witwatersrand, South Africa \\ E-mail: emuremasoke@gmail.com \\ Laura Dison ${ }^{1}$ iD \\ School of Education, University of the Witwatersrand, South Africa \\ E-mail: laura.dison@wits.ac.za \\ Wacango Kimani \\ School of Education, University of the Witwatersrand, South Africa \\ E-mail: wacango@gmail.com \\ Halima Namakula \\ School of Education, University of the Witwatersrand, South Africa \\ E-mail: hknamakula@gmail.come
}

\begin{abstract}
Writing centres in South African universities have historically been poorly recognised structures in higher education, and have largely been considered as "asides" to the core functions of the university. This lack of acknowledgement has seen writing centres occupying demeaning physical spaces within universities which has had a negative impact on the full potential of writing centre work. This narrative study focuses on the experiences of three postgraduate writing consultants, and reports on the ways that the Writing Centre at the Wits School of Education (WSoE) has exerted agency in order to move from a marginalised position in a school of education to reach students and become more responsive to their needs. While being proactive has yielded many teaching and learning gains at the WSoE, the Writing Centre has also had to contend with various personal and operational tensions such as deficit perceptions from both staff and students, and unrealistic expectations of students that their writing problems will be solved instantly. These challenges, however, have created opportunities for growth of the Writing Centre as it has developed new pathways for consultants in the shift from generic writing consultations to content-specific writing development. The changed model has had implications for the training and pedagogies of writing centre
\end{abstract}

\footnotetext{
${ }^{1}$ Corresponding author.
} 
consultants as well as for their identity as students and mentors. This article provides insights into how writing centres can use their agency to occupy more meaningful spaces and places within universities, and enhance academic literacy support whilst simultaneously providing writing consultants with opportunities to grow their scholarship.

Keywords: writing consultants; writing centre; agency; narrative; writing in the disciplines

\section{Introduction}

Writing centre models of intervention in writing development in South Africa have changed constantly in the past 30 years in light of the shifting contexts of the universities in which they work (Clarence and Dison 2017). As senior writing consultants, we argue that it is important to gain a sense of the changes in the writing centre practice at the Wits School of Education (WSoE) to understand the impact these changes have had on our roles and identities. Our experiences are foregrounded as we narrate our experiences of overcoming some of the challenges we face in our position as writing consultants. These experiences demonstrate the capacity of the WSoE Writing Centre to exert its agency in becoming more responsive to students' needs, especially in the context of a first-year writing intervention programme. This article addresses the tensions underpinning writing centre practice as writing consultants are required to adjust their roles in disciplinary spaces and places. It begins with a historical account of the model adopted by the WSoE Writing Centre from the perspective of the Writing Centre coordinator, followed by an analysis of the ways in which we have negotiated and resolved some of the pedagogical and identity issues we face. This analysis is part of an ongoing conversation about the transformative potential of writing centres and the agents who participate in their changing spaces and places.

\section{The Wits School of Education Writing Centre model}

The WSoE Writing Centre, which was established in $2010^{2}$, selects and trains senior Education students as writing consultants to develop students' academic writing abilities and their understanding of literacy in the classroom as future teachers. This was in line with a national trend towards writing centres in a context of persistent and high student drop-out and failure rates. It was acknowledged that something had to be done about the "failure of the school system to prepare pupils for further study" (Scott 2017), and that universities needed to focus on sustained development of academic literacies for success in higher education.

The Writing Centre situates itself within the field of academic literacies which challenges deficit constructions of students, and which signals a "critical approach to the researching and teaching of writing and literacy and to the role and potential of these activities for individual meaning making and academic knowledge construction in higher education" (Lillis, Harrington, Lea and Mitchell 2016: 4). It adheres to the writing centre model of inquiry and negotiation (Archer and Richards 2011) which enables students to reflect critically on their writing processes as active participants in conversation with consultants. In consultation sessions at the Writing Centre, students respond to discovery questions and suggestions for improving their assignments in order to make their writing more concise and clear to their

\footnotetext{
${ }^{2}$ The WSoE Writing Centre has never been supported financially by the university, and is funded by the Council of Education with some limited funding from the University Capacity Development Grant.
} 
readers. Academic literacy goes beyond generic reading and writing, and is seen to act dynamically in response to the needs of disciplinary contexts. Consultants learn how to engage with their clients as mediators and co-constructors of knowledge in understanding the elements of academic argument underpinning specific genres.

The advantages of locating the Writing Centre in the WSoE were practical as the students would not have to travel to main campus for consultations, and with the recognition that Education students have particular discourse requirements and demands that are best mediated by writing consultants who have an intimate knowledge of the course content and the assessment task demands in the field of education. Familiarity with disciplinary content gives writing consultants access to key conceptual misunderstandings although they have been trained to withhold from interpreting or teaching, and to allow students to be the directors of their own writing as much as possible. In terms of the training, consultants are introduced to an interactive, dialogic approach for engaging with students around their essay drafts through a weekly training programme. Education-based writing consultants ${ }^{3}$ learn to facilitate the writing development of undergraduate and postgraduate students by asking probing questions that engage students in conversation about their writing and through goal-specific suggestions for improving their essays. The nature of this training has evolved in line with consultants' changing roles as will be discussed later in the article. Before the establishment of Project Write Up Read Up (WURU), a traditional "drop-in" model existed where Education students would make individual appointments to discuss specific essays with individual writing consultants ${ }^{4}$.

\section{Project WURU: First-year Writing Centre intervention for "at risk" students}

In 2014, the WSoE initiated a major writing intervention in the context of a compulsory theoretical first-year course. This writing-intervention course was located at the Writing Centre, embedded in Education Studies, and came about as a result of a collaborative process with Education lecturers. The university had to deal with an increase of approximately 250 Education students in 2014, and had concerns regarding the academic readiness of first-year students. They therefore commissioned the University of Cape Town to administer the Academic Literacy component of the National Benchmark Test (NBT). Of the entire cohort, 120 first-year students who scored below $40 \%$ for the Academic Literacy test were selected for the special intervention programme. The programme was designed in early 2014 using pointers from the diagnostic analysis of students' weak performance areas. WURU was initiated as a support programme for first-year Education students, and was closely aligned to the Education I curriculum. From 2014 to 2017, 120 first-year students identified as needing assistance were invited to attend weekly sessions run by writing consultants. In these sessions, both generic and practical skills with regard to academic reading and writing were taught as well as guidance provided in relation to the Education I course work and assignments. The Writing Centre conducted joint writing workshops with course lecturers to unpack assignment criteria and build strategies for concept and vocabulary development. From our experience in 2014 and 2015, a formalised programme for "at risk" students facilitated the development of strong academic discourse and skills in the

\footnotetext{
${ }^{3}$ The selection criteria for writing consultants include, amongst others, levels of writing proficiency, confidence, experience in working with students, and commitment to the programme. It is interesting that a steady pool of proficient and confident consultants is always available through word of mouth, and through peer and lecturer referral as a number of consultants graduate each year.

${ }^{4}$ This one-on one consultation service is still available to students.
} 
student group which suggested the adoption of a more explicit academic literacy focus for the benefit of all first-year students in the tutorial programme.

\section{Mainstream tutorials}

In 2015, after a second round of analysing the diagnostic information from the NBT, it was decided, in conjunction with course lecturers, that the mainstream tutorials would become the key focus of WURU activities. Although WURU students, selected on the basis of their NBT results $(40 \%$ and below), continued to be placed in "specialised" groups at the Writing Centre, the tutorials were geared to accommodate the educational needs of students across the range of abilities. The Writing Centre coordinator, together with the course lecturers, designed text-based materials on a weekly basis aligned with the prescribed tutorial questions and readings in tutorial spaces.

\section{Project WURU reconceptualised: First-year Writing Centre intervention open to all students}

Since 2018, the selection criteria for WURU were modified to accommodate more students as a result of the perceived success of the intervention. Besides providing academic support, almost all of the first-year students indicated in feedback questionnaires that they had experienced a huge confidence boost from the WURU programme, and results indicated that students who attended weekly WURU sessions performed approximately $4 \%$ better than students not selected for the programme ${ }^{5}$. It was decided to allow first-year students to join the programme voluntarily. Not only did students sign up willingly and in large numbers, but the fact that it was voluntary seemed to remove the negative stigma attached to being "invited" to a programme that many in previous years had viewed as being for those who could not "cope". The number of WURU students has escalated from about 100 students from 2014 to 2017 to an excess of 300 in 2018 and 2019.

The current model is that WURU students are invited to attend a 45-minute-long, small, weekly group session for the duration of the academic year. These sessions are run by writing consultants, and skills and processes with regard to both academic reading and writing are taught in the context of Education I course work and assignments. Weekly training sessions are dedicated to preparing writing consultants to work in a structured way with their allocated WURU groups. Furthermore, writing workshops run by writing consultants are scheduled for large numbers of first-year students, and focus on referencing conventions and exam preparation strategies within lectures and during lunchtimes.

\section{Review of literature}

It is well documented in the literature that writing centres have been concerned with the issue of marginality as their contribution and importance has not been well recognised within the academy (Archer and Richards 2011, Hemmeter 1990, McKinney 2013). Writing centre work, in many of the worlds' higher education institutions, has always been seen as secondary to these institutions' teaching and learning functions. According to Hemmeter (1990), writing centres have a secondclass status which often manifests in poor staffing, and operating with inadequate budgets and in the peripheral physical spaces they are made to occupy such as dark, windowless basements.

\footnotetext{
${ }^{5}$ These were students who scored higher on the NBT Academic Literacy test component, and who mostly had higher matric scores.
} 
Pragmatically, higher education institutions have relegated writing centre work to the margins. In an attempt to explain this endemic marginalisation, Hemmeter (1990) points out that the processes of reading and writing have long been thought of as individual processes that do not require assistance for mastery of the "skill". This perception has also been raised by Murphy and Law (1994) who indicate that higher education institutions have never been convinced about the role and contribution of writing centres, and have viewed them as separate entities outside of the lecture hall.

As a result, writing centres have had to negotiate legitimacy within the academy by adopting self-defining practices and scholarship that seek to accentuate their contributions to the educational process. Carino (2002) explains that writing centres are positioned between innovation and marginality where they have had to use innovative strategies to remain relevant in higher education institutions that are threatened with funding cuts and closure. These constraints necessitate the use of agency to create and claim space amidst contestation within the university space (Daniels, Richards and Lackay 2017). For example, the move from generic academic literacy development towards content and discipline-specific approaches is one strategy that is being widely used by practitioners in writing centres to negotiate acceptance in the academy. Clarence and McKenna (2017: 39) make the observation that, while offering generic academic literary support is still useful, it is more relevant for academic development practitioners to adapt their practices to effectively meet the needs of students who are "creating varied disciplinary texts, reading within specific disciplinary 'cannons' or bodies of knowledge". Thus far, this negotiating tool of working within the disciplines is proving to validate writing centres as academically respected organisations within the academy. The question of legitimacy within the academy, however, remains an issue of concern as writing centre practitioners are asking themselves: "[...] how do we get from the outside in, and make our contributions count when we get there?" (Clarence and Dison 2017: 6).

While writing centres are negotiating entry into the disciplines, they are at the same time grappling with ensuring access to writing centre services to the ever increasing student population. South African universities have seen increased student enrolments due to the broadening of educational access since the early 1990s, and the university space is generally experiencing problems associated with large class sizes (Archer and Richards 2011). Shabanza (2017) points out that deep engagement and accommodating student diversity are some of the challenges emerging from large class sizes which have also made their way into writing centres. Writing centres have had to deal with the large influx of students against the background of poor resources and lack of support from the universities. Many writing centres are currently incorporating group consultations in an attempt to deal with the overwhelming student numbers. Inevitably, this exerts pressures on writing consultants as well as presenting challenges to the traditional writing centre Socratic pedagogy that works well in one-on-one consultations (Nichols 2017).

Nevertheless, working with groups of students has created opportunities for writing centres to be innovative for the benefit of a broad range of students, thus validating these centres' existence within the academy. According to Wilmot and McKenna (2018), this group setting has brought about a new socio-cultural understanding of literacy development where peer engagement amongst students creates conducive, horizontal, peer-orientated spaces for learning. This is consistent with Nichols (2017: 39) who argues that writing centres should be free spaces that afford students the opportunity to "think through conflict". In other words, students can work in cohorts in an environment that encourages rigorous debate as they work 
towards a solution. In Wilmot and McKenna's (2018) words, working in groups renders the writing centre a transformative space that plays a key role in developing the individual student through engaging in explicit discussions on academic practices. They further assert that the writing centre is the only space within the academy where academic practices and conventions are challenged and confronted without being tied to any evaluation or assessment.

Working against a backdrop of marginalisation, we argue that the WSoE Writing Centre has ventured into new spaces within the university and, in the process, has embraced innovative approaches to consultant training and consulting pedagogies. This article explores the use of the Writing Centre's agency and the implications that this has had on the consultants' practice and identity, something that has not been extensively covered in writing centre practice literature.

\section{Study design: Reflective narratives}

This study seeks to understand our experiences as writing consultants as the Writing Centre negotiates new ways of working in the disciplines. It provides a vehicle for us ${ }^{6}$ to reflect on our experiences of the "new" ways in which we operate in writing centre spaces. The reflective narratives showcase our experiences and the meanings we attribute to those experiences. In understanding the underlying meaning of our experiences in context, through our narratives, the inquiry broadens our knowledge of the Writing Centre's new role in promoting writing development in the disciplines. The inquiry raises further questions about the type of training new consultants need to undergo in order to address the changing ways of operating in the disciplines, and points to other forms of inquiry needed to make the Writing Centre's work more visible and impactful.

Narrative inquiry is appropriate for this study because, as writing consultants, we wish to use the same strategy we ask our students to engage with when we want them to "unpack their thinking" as a form of the "writing as thinking" process (Nichols 2011: 94). Therefore, writing and formulating our own experiences has allowed us to "think" through our ideas. Additionally, we agree with Merriam and Tisdell (2015: 33) who state that "stories are how we make sense of our experiences, how we communicate with others, and through which we understand the world around us". Stories are meant to reveal the storytellers' identities, and, when interpreted, provide an in-depth understanding of the world that created it. Stories are a means of making sense of past experiences, and they show the significance of the experiences in the context of their enactment.

This design is also appropriate because "the practice of doing education and finding out about education are inextricably bound together" (Scott 2002: 155). With self-reflection, we educated ourselves about our practice, and also developed understandings of education, in this case, how the writing centre is accomplishing its mandate. Drawing on Ricœur's (1991) notion of 'narrativity', Scott (2002) posits that while locating themselves in the present, researchers revise and rework the past through narrative versions of their past. This makes the account of the past a lived account, creating a "dialectical relationship between the practice of education and research" which is a distinguishing feature of narrative research. The narratives located in the "practice of education [are] reflexively made" (Scott 2002: 155).

\footnotetext{
${ }^{6}$ All three consultants have worked in the Writing Centre for over five years; two are PhD students while one has recently obtained her doctorate.
} 
The research participants in narrative design may speak or write biographical information related to the phenomenon that is being investigated. Bolton (2010) suggests that writing enables proper listening to ourselves through reflection and reflexivity. She further distinguishes between reflective and reflexive practices, with the former a way of paying critical attention to the values and theories which inform everyday actions, and the latter a way of standing outside the self to examine assumptions and the limits of our knowledge (Bolton 2010). While reflecting, we review and relive past events while considering our feelings and those of the people involved. Reflexivity is needed in order to bring about change to "deeply held ways of being" (Bolton 2010: xix), and is the critique that can enable change.

Stories enable reflection and reflexivity because they have a "unique power to make sense of issues" (Bolton 2010). Not only do stories enable understanding of deeply held feelings, but they also provide insights from different perspectives when they are written. Writing stories enabled us to question our assumptions as we explored how our experiences matter. Using reflective narratives, three consultants, as authors of this article, share our experiences and lessons learned from working in new spaces within the WSoE Writing Centre. After writing our storied reflections, we reviewed the texts and identified "meaningful episodes" (Moen 2006: 62) that characterised the Writing Centre's agency which we classified into three spaces, namely (i) working in the disciplines, (ii) enacting a group pedagogy, and (iii) participating in mainstream tutorials.

\subsection{Space 1: Working in the disciplines: Education Studies}

The WSoE Writing Centre has extended its academic literacy support into the disciplines through WURU. This has been a significant shift from working with individual students who bring essays to the Writing Centre from a range of Education disciplines at undergraduate and postgraduate levels, to working within the context of a specific course, namely Education Studies. We narrate our experiences of working within the disciplinary context of Education Studies below. (Our comments are not presented in the same order in each of the spaces.)

\section{Consultant 1}

My experience of working in a more contextualised space like Education Studies is rewarding for students because they get to deal with the actual content of the course and with what is taught in lectures. This, in the process, gives students the opportunity to work with key concepts and to understand how to integrate the academic literacy skills provided to them in the Writing Centre. I am able to draw from content, and use examples that make it possible for students to see the links, and they can connect with that. As much as there have been benefits, for me as a consultant, this inclusion of academic support into the Education Studies course has challenged me in two ways: 1) It has required me to engage with the Education Studies content, and that has meant sometimes attending the lectures before meeting with my group of students which requires time. 2) There is also a huge responsibility and expectation placed on me as a consultant to be more knowledgeable in the subject. As a result, students expect me to deliver where they think they fall short. This has created fear in me as a consultant of not wanting to look "stupid" in front of the students because you have done this course before and you should know the content better than the students. Despite all this, I still 
think the integration of Education Studies into WURU has been the right move because this provides students with an opportunity to gain access to the academic discourse.

\section{Consultant 2}

My experience of working with first years in WURU can best be described as bittersweet. Why bitter? Firstly, I found it extremely time consuming to prepare for my WURU sessions. At one point, I was assisting the Writing Centre coordinator to develop the material and activities, and this meant I had to keep abreast, if not ahead, with the reading of the course material. I also had to attend Education Studies lectures so as to get a better sense of the lecturer's requirements of the students. This was especially overwhelming given the fact that I was pursuing my own postgraduate studies, teaching other courses, and involved in a research project. The sweet, enjoyable moments were the learning and growth curves that came with this stretching. I must say I learnt a lot about myself as a budding academic working within the academic literacy space in terms of embedding academic literacy skills into a particular discipline. I was especially thrilled with the students' newfound enthusiasm with academic literacy. Clearly, students were more drawn in because the learning was now contextualised, and they could see how it was helping them cope with, supposedly, the most difficult course at Wits University.

\section{Consultant 3}

While I can discuss the generic skills with relative ease, I find I need to read a lot more when I discuss academic writing in the first-year course, Education Studies. To discuss the essay structure within specific subjects confidently requires reading the course readers. Students find much more benefit when discussions are geared to a specific subject or specific essay. Seeing how well the students understand various aspects of academic writing is fulfilling but requires a lot more preparation.

It appears from these accounts that we were excited and energised by the prospect of enhancing students' academic literacy development through the creation and implementation of a discipline-based writing project. The embedded intervention has gone a long way to adopt the principle that academic writing, like other forms of writing, needs to be tailored to its specific context, purpose, and audience. Learning, as Wingate (2006) puts it, should not take place outside the subject content, and the discipline-based academic literacy development contextualises the learning for students and increases their chances of academic success. The point that academic problems are "typically rooted within a disciplinary conversation" (Bean 2011: 3) implies that consultants need to help students draw on their content knowledge as well as on knowledge about the discipline's methods of argument and evidence.

This move to embedded approaches is not without its challenges, and we are constantly recalibrating our roles as subject vs writing specialists when faced with students' increasing demands. The success of the intervention depends strongly on our ability to transcend a view of academic writing as a "communication skill" or a "discrete skill that can be taught outside of the content of the discipline" (Clarence 2012: 129). Given that effective academic writing necessitates that student writers (less competent persons) clearly understand the specific requirements of the task, then our (more competent persons) main role is to help them decode disciplinary arguments, kinds of evidence, and genre conventions. As pointed out in our 
narratives in the section, this is more demanding as we believe that we need to be more prepared. It also raises questions about the quality and skills of subject tutors ${ }^{7}$.

\subsection{Space 2: From individual consultations to enacting small-group pedagogies}

As discussed in the introduction, the initiation of WURU groups, initially for "at risk" students but now inclusive of all first-year Bachelor of Education students, has heralded a significant shift from individual consultations to weekly, planned, small group sessions with an assigned writing consultant. These group sessions are held at the WSoE Writing Centre, and have become increasingly structured around interactive contextualised materials developed in collaboration with Education Studies course lecturers. The pedagogy uses text-based design in which students engage in reading and writing activities that prepare them for the assignment requirements. This section begins with an analysis by Consultant 3 .

\section{Consultant 3}

During the second semester of my second year at the Writing Centre, the School requested the Centre to develop an intervention for almost 100 students who were at risk of academic exclusion. When I interacted with these students, I learned that the Writing Centre was perceived as a place for "failures". This deficit perception discouraged most of them from seeking help as they did not want to appear "stupid". The intervention included several workshops on studying and preparing for exams. The workshops were well attended, and students reported that workshops had helped them pass their first year. This short intervention showed that there was a need to tackle students' academic literacy from the beginning of the year.

To deal with students' academic literacy from the beginning of first-year, the Writing Centre established the WURU programme in 2014 after identifying students who performed poorly on the NBT test. These students were encouraged to attend weekly group sessions at the Writing Centre. I was assigned two groups, and while most of the identified students attended their WURU sessions, the deficit perception of the Writing Centre persisted. To change this perception, I had each group choose a motivational name to describe the group. At the beginning of the sessions, I would give a short peptalk to encourage the students to keep attending the sessions. My other challenge with the group sessions was how to provide a writing consultation to a group without being an instructor or teacher. Having been a teacher, I was often inclined to teach rather than facilitate the WURU sessions.

\section{Consultant 1}

Before I could do my own consultations, I had an opportunity to shadow a consultant with a group of first-year students. I could see the nervousness and fear in these students but I also saw how the consultant tried to ease their anxiety about academic writing and reading. She would ask the students questions, and I wondered how I would be able to do that without the teacher in me coming out. As time went on, I came to realise that it actually helps them to think. Instead of giving them the answers, you get them to think

\footnotetext{
${ }^{7}$ These subject tutors are often senior students who have been awarded merit bursaries.
} 
about their choices. For example, students begin to think deeply about their writing: Why have I started my introduction like this and not that way? How can I improve my draft? Why should I remove this information and add this other information? Is this an argument I am making? Where is the evidence for the claims I am making? How do I avoid regurgitating what is exactly in the article? Is this quote necessary?

It was very difficult at the beginning to work with a group of students but the ongoing training and workshops we receive as writing consultants empower us with different strategies and methods to use during consultations. It has been a journey of highs and lows because different students come with different needs and attitudes, and require you to be ready to deal with all that. My philosophy as a writing consultant has always been to see students as different, and it is my responsibility to make sure that I provide a space in which they can trust me, feel motivated, and that allows interaction. This is what I tried to do with the group of students.

\section{Consultant 2}

Our Writing Centre first considered doing group consultations when we were confronted with huge traffic of students at the Centre. This was especially the case a few days before a first-year assignment was due. In panic, the students would flood the Writing Centre, and conducting individual consultations was just impractical. Besides, more often than not, most, if not all, students would come with very similar concerns. We then decided to attend to them in groups of up to six or eight.

My initial encounter with groups was very difficult because it was very open-ended, and I tried to work with the group the best way I saw possible. It was not long before the formal inception of WURU. The challenges of working with the groups persisted, and it was becoming apparent that we needed to impose more structure in order to work with groups of students more fruitfully. Our coordinator went on to develop material for use in the group sessions that spelt out specific activities that were to be covered in each session. That brought much clarity and ease in working with groups of students.

While I have been able to overcome some challenges, to this day I still find working in group consultations difficult. For example, some students are too domineering while others are passive. Balancing this out is still a challenge for me. Then there is the issue of confidentiality where sometimes you cannot engage with students' writing because some are not comfortable sharing their work in a group. I must say that I have benefited a lot from the continuous training we get as writing consultants. New insights from the training have boosted my confidence in the way that I consult with either WURU or student groups in general.

WURU has disrupted the "quick fix" conception of the WSoE Writing Centre by Education lecturers who refer their students to the Centre to "improve their writing and grammar". It also recognises that students will not always be in a position or have agency to seek external support and draw on resources for their writing development. WURU thus presents a workable solution to the negative positioning of students as "de-contextualised learners" independent of their history and culture (Boughey and McKenna 2016). From the students' weekly responses, attending WURU sessions often made the difference between passing and failing essays, and 
they have appreciated our focus on their writing development in a supportive environment. However, our narratives capture a new set of challenges we face as we develop strategies for accommodating diverse writing needs in the groups. The regular and ongoing training to prepare us to handle group sessions has addressed some of these anxieties, as the Writing Centre coordinator and course lecturer guide consultants through the reading- and writing-embedded materials which have also been incorporated into mainstream tutorials.

\subsection{Space 3: Tutorial space}

Course lecturers in Education Studies have recognised the need for a more structured approach to mainstream tutorials as a result of large student numbers (over 550 students in first-year), and subject tutors who are often senior Education students with little or no background in the field of Education Studies. They have also acknowledged the value of writing consultants in tutorial spaces who can assist students to write purposively using the writing-embedded tutorial materials. The accounts below are from Consultants 1 and 3 who have worked in the mainstream tutorial spaces.

\section{Consultant 1}

Working as a writing consultant in the tutorials has been a valuable working experience. Working as a "shadow" to the main tutor has given me an opportunity to develop skills with managing a large group of university students. It is also encouraging when students from my tutorial group later come to the Writing Centre seeking assistance with their essays. However, managing students' expectations is difficult. Students expect that they should obviously get very high grades, since they have attended tutorials, and even sought help from me at the Writing Centre.

\section{Consultant 3}

When the request was made to assist in the WSoE's mainstream tutorials, I was anxious and nervous about this role or position. Assisting in the tutorial for me added another layer of responsibility on a larger scale because you are not dealing with a few students but a group of 30-50 students in a tutorial and, as mentioned earlier, all stakeholders involved expect you to deliver. You are thrown into a space where you must navigate a new relationship with the tutor. This becomes tricky especially when you are in a position of having more knowledge than the tutor and students draw to you more than the assigned tutor. For me, working in tutorials meant a shift in my role as a consultant because you are not in charge but an assistant to the tutor. As an assistant, sometimes you find yourself playing it safe because you don't want to take over the tutorial even when you see the tutor struggling to explain certain concepts. That makes it difficult standing by and watching.

Navigating between these roles has been difficult because of not knowing which side I represent or whether I have the knowledge and capacity to fulfil both roles, and whether I can claim to know enough that warrants me to offer support to a fellow student. This "inbetweenness", when in a tutorial space, is difficult to manage or overcome, and has implications in the way you interact with the students (some of which are part of your WURU group in the Writing Centre), and here you are taking a backseat instead of leading. 
Thus, for me, moving in the tutorial space as writing consultant brought both some excitement of being able to help others as well as anxiety as I often have worries and fears of not being able to deliver what I was hired for. It is something that has challenged me, and I have tried to navigate and negotiate these different roles and different spaces and places within the Writing Centre. However, there is a light at the end of the tunnel! I believe I have managed to find a way to deal with this challenge. Instead of viewing it as a challenge, I see it as an opportunity in which I can offer students my experience as a student, and help them navigate the academic discourse.

Although we work in spaces which enhance writing development for all students in mainstream tutorials, contextual constraints such as the lack of and poor background knowledge of subject tutors, and large first-year tutorial groups (45-50 per group) exacerbate the pressures we face to perform predominantly as content experts. It is evident from an analysis of student essay results and lecturers' comments collated by the Writing Centre that this reading and writing dimension has provided an invaluable service to undergraduate students. An important spin-off has been that the Writing Centre coordinator has worked collaboratively with subject specialists to develop discipline-based literacy practices through prescribed texts and tasks. The collaboration between writing/assessment specialists and course lecturers has also resulted in the reformulation of assessment tasks and rubrics based on learning-orientated assessment practices (Carless 2015).

\section{Discussion and conclusion}

In this article, we have tried to showcase how, in our role as writing consultants, we have participated in and experienced changing spaces and places at the WSoE Writing Centre. Our narratives tell stories of our struggles as well as successes within and outside the writing centre spaces. Our argument is that the changes in the WSoE Writing Centre's modus operandi impact the role and identity of consultants more generally. Our article shows how these moves from the periphery into discipline-specific spaces may create tensions but at the same time provide opportunities for us to act as experts (Elbow 2000) for enabling student academic success. One of the exciting developments has been to see how the WSoE Writing Centre has built the capacity of undergraduate and postgraduate consultants to work with students in these multiple spaces. The training programme has geared itself to the shifting context and to developing consultants to reflect systematically on their own writing and consulting processes using evaluative tools. Writing consultants on the whole have reported on how these ongoing learning experiences have deepened their own writing and mentoring expertise.

In conclusion, we return to the argument made by Archer and Richards (2011: 9-10) that "writing centres have the potential to be agents of change [and that] keeping writing pedagogy in writing centres is not ultimately our goal". We concur with their argument that we need to find ways of working in disciplines that promote critical reading and writing practices, and to transform higher education more broadly. A fully resourced and responsive writing centre can promote reading and writing development within the specific context of Education disciplines for undergraduate students as well as afford lecturers the opportunity to address the specific needs of their students in relation to their curricula, teaching, and assessment practices. The experiences we have narrated show the potential for these meditational processes to enhance academic literacy practices powerfully within the context of Education courses provided that these processes are acknowledged and supported institutionally. 


\section{References}

Archer, A. and R. Richards. 2011. Writing centres as alternate pedagogical spaces. In A. Archer and R. Richards (eds.) Changing spaces: Writing centres and access to higher education. Stellenbosch: African Sun Media. pp. 5-16.

Bean, J. 2011. Engaging ideas: The professor's guide to integrating writing, critical thinking and active learning in the classroom. San Francisco: Jossey-Bass.

Bolton, G. 2010. Reflective practice: Writing and professional development. London: Sage Publications.

Boughey, C. and S. McKenna. 2016. Academic literacy and the decontextualized learner. Critical Studies in Teaching and Learning 4(2): 1-9.

Carino, P. 2002. Reading our own words: Rhetorical analysis and the institutional discourse of writing centres. In P. Gillespie, A. Gillam and L.F. Brown (eds.) Writing centre research: Extending the conversation. London: Routledge. pp. 91-110.

Carless, D. 2015. Excellence in university assessment: Learning from award-winning practice. London: Routledge. https://doi.org/10.4324/9781315740621

Clarence, S. 2012. Making inter-disciplinary spaces for talk about and change in student writing and literacy development. Teaching in Higher Education 17(2): 127-137. https://doi.org/10. $\underline{1080 / 13562517.2011 .611876}$

Clarence, S. and L. Dison (eds.) 2017. Writing centres in higher education: Working in and across the disciplines. Stellenbosch: African Sun Media.

Clarence, S. and S. McKenna. 2017. Developing academic literacies through understanding the nature of disciplinary knowledge. London Review of Education 15(1): 38-48. https://doi.org/ $\underline{10.18546 / 1 r e .15 .1 .04}$

Daniels, S., R. Richards and A.-M. Lackay. 2017. The Writing Lab in the Centre: A collaborative model of integrating writing consultations in a first-year Engineering module. In S. Clarence and L. Dison (eds.) Writing centres in higher education: Working in and across the disciplines. Stellenbosch: African Sun Media. pp. 129-144. https://doi.org/10.18820/9781 $\underline{928357551}$

Elbow, P. 2000. Everyone can write: Essays towards a hopeful theory of writing and teaching writing. New York and Oxford: Oxford University Press.

Hemmeter, T. 1990. The "smack of difference": The languages of writing centre discourse. The Wring Centre Journal 11(1): 35-48.

Lillis, T., K. Harrington, M. Lea and S. Mitchell. 2016. Working with academic literacies: Case studies towards transformative practice. Fort Collins: The WAC Clearinghouse and Parlor Press. 
McKinney, J.G. 2013. Peripheral visions for writing centres. Boulder: Utah State University Press.

Merriam, S.B. and E.J. Tisdell. 2015. Qualitative research: A guide to design and implementation. San Francisco: Jossey-Bass.

Moen, T. 2006. Reflections on the narrative research approach. International Journal of Qualitative Methods 5(4): 56-69.

Murphy, C and J. Law. 1994. Landmark essays on writing. New York: Routledge.

Nichols, P. 2011. A snowball in Africa with a chance of flourishing: Writing centres as shifters of power in a South African university. In A. Archer and R. Richards (eds.) Changing spaces: Writing centres and access to Higher Education in South Africa. Stellenbosch: African Sun Media. pp. 91-100. https://doi.org/10.1080/1013929x.1998.9678044

Nichols, P. 2017. Writing democracy: From writing centres to writing fellows to writing intensive courses in a university-wide writing programme. In S. Clarence and L. Dison (eds.) Writing centres in higher education: Working in and across the disciplines. Stellenbosch: African Sun Media. pp. 35-48. https://doi.org/10.18820/9781928357551

Scott, D. 2002. Ethnography and education. In D. Scott and R. Usher (eds.) Understanding educational research. London: Routledge. pp. 143-158.

Scott, I. 2017. Core issues besides finance and access hinder students' success. Available online: https://mg.co.za/article/2017-10-20-00-core-issues-besides-finance-and-access-hinderstudents-success (Accessed 2 April 2019).

Shabanza, K.J. 2017. Enhancing reflection on writing: Using group writing consultations to develop meta-awareness of disciplinary writing. In S. Clarence and L. Dison (eds.) Writing centres in higher education: Working in and across the disciplines. Stellenbosch: African Sun Media. pp. 161-174. https://doi.org/10.18820/9781928357551

Wilmot, K. and S. McKenna. 2018. Writing groups as transformative spaces. Higher Education Research and Development 37(4): 868-882. https://doi.org/10.1080/07294360.2018.1450361

Wingate, U. 2006. Doing away with "study skills". Teaching in Higher Education 11(4): 457-469. https://doi.org/10.1080/13562510600874268 